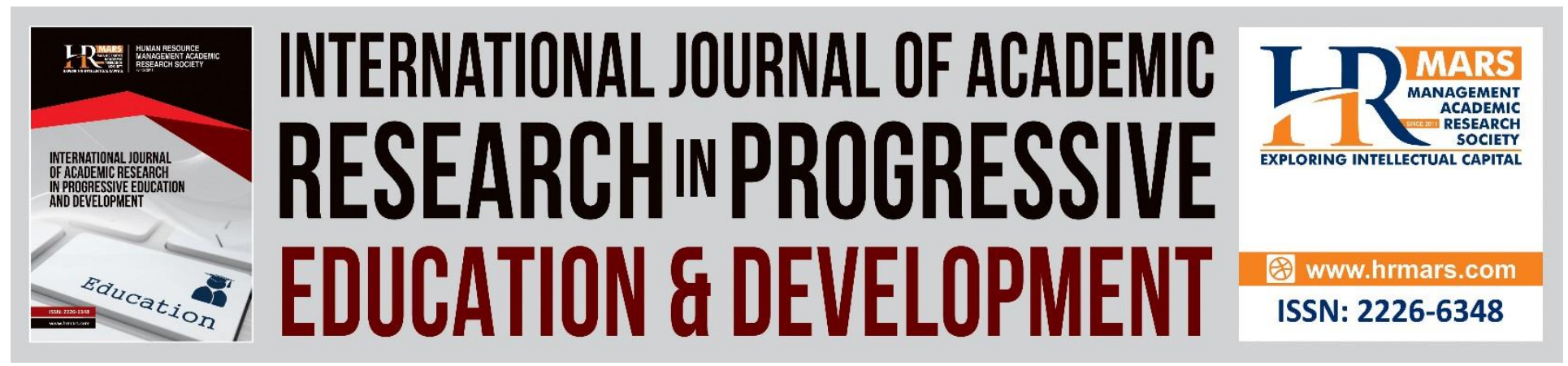

\title{
Understanding Students' Metacognition in Mathematics Problem Solving: A Systematic Review
}

\section{Sebestian Kalang William \& Siti Mistima Maat}

To Link this Article: http://dx.doi.org/10.6007/IJARPED/v9-i3/7847

DOI:10.6007/IJARPED/v9-i3/7847

Received: 11 August 2020, Revised: 22 September 2020, Accepted: 16 October 2020

Published Online: 28 October 2020

In-Text Citation: (William \& Maat, 2020)

To Cite this Article: William, S. K., \& Maat, S. M. (2020). Understanding Students' Metacognition in Mathematics Problem Solving: A Systematic Review. International Journal of Academic Research in Progressive Education and Development, 9(3), 115-127.

\section{Copyright: (C) 2020 The Author(s)}

Published by Human Resource Management Academic Research Society (www.hrmars.com)

This article is published under the Creative Commons Attribution (CC BY 4.0) license. Anyone may reproduce, distribute, translate and create derivative works of this article (for both commercial and non-commercial purposes), subject to full attribution to the original publication and authors. The full terms of this license may be seen

at: http://creativecommons.org/licences/by/4.0/legalcode

Vol. 9(3) 2020, Pg. 115 - 127

Full Terms \& Conditions of access and use can be found at http://hrmars.com/index.php/pages/detail/publication-ethics 


\title{
LR \\ INTERNATIONAL JOURNAL OF ACADEMIC \\ RESEARCHINPROGRESSIVE \\ EDUCATION \& DEVELOPMENT

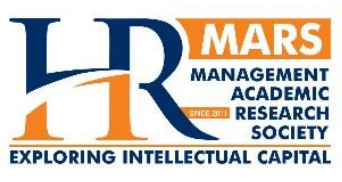 \\ INIERNATIONAL JOURNAL
OF ACADEMIC RESEARCH
IN PROGRESIVE EDICATIOH \\ AND DEVELOPMENT \\ EquCation \\ Understanding Students' Metacognition in Mathematics Problem Solving: A Systematic Review
}

\author{
Sebestian Kalang William \& Siti Mistima Maat \\ Faculty of Education, Universiti Kebangsaan Malaysia \\ Email: sebestian.william@stjosephkuching.edu.my, sitimistima@ukm.edu.my
}

\begin{abstract}
The ability to be aware and monitor one's cognitive progress proven to be very beneficial especially when students attempt to solve mathematical problems. In the absence of these skills, an individual will not properly plan, sequence, and monitor their learning. Therefore, this study was conducted to understand students' metacognition when they approach mathematical problems by reviewing past literature systematically within the study context. This review was conducted by gathering literature published from the year 2017 to 2020 recently from two known databases that are ERIC and Scopus. Final screening provides this study with a total of 31 articles, which has been chosen based on the inclusion and exclusion criteria set by this study. Findings from the review of this study identified characteristics of mathematics problem, integrated learning, class activities, integrating software during mathematics problem-solving, students' factor, teacher and supplementary elements as the factors influencing the students' metacognition. Consequently, the students and their teachers were found to be the source of the challenges faced by students as they employ metacognition. Hence, metacognition can be improved and nurtured as the challenges are addressed to let students reap the benefits that contribute to the progress in solving a mathematical problem.
\end{abstract}

Keyword: Mathematics, Problem Solving, Metacognition, Metacognitive, Systematic Review

\section{Introduction}

The ability of the students to monitor their thinking is proven to be beneficial to help the students during their problem-solving. In mathematics problems, it was shown that students that were taught based on metacognitive and self-regulating strategies achieved better results compared to the one with different instruction (Vula, 2017; Ahdhianto et. Al., 2020). Besides, research was done by Ozdogan, Ozcakir, and Orhan (2019) identifying the metacognitive behaviors of students shown that successful problem solvers showed more metacognitive behaviors than the less successful ones and this behavior include re-reading the problem given. This is supported by Tachie and Molepo (2019) as metacognitive skills help learners to synthesize valuable information related to problem-solving. Nevertheless, another approach was using 
metacognitive discourse on students and it shows that these students outperformed the students that were only exposed to the mathematics discourse on mathematical problem-solving performance (Shilo \& Kramarski, 2019).

In contrast, the absence of this awareness would not maximize the students' learning and influence their skills in solving mathematics problems (Setiawan \& Supiandi, 2018). Without the awareness of monitoring their cognitive progress, children solve mathematics problems without proper analysis of the question and strategy to solve the problem as they tend to jump to the mathematical operation to be applied (Bessoondyal, 2017). Besides, children tend to overestimate their abilities as they were only able to monitor their performance modestly (Nelson \& Fyfe, 2019). This may affect the students' mathematics performance as Hanin and Van Nieuwenhoven (2020) reported below-average students to have a very poor collection of cognitive strategies as they were seen solving mathematics problems with a general or no strategy at all. They further explained the lack of cognitive strategy of the below-average students affects their level of confidence as they were repeatedly made mistakes. These mistakes can be improved when the students develop their metacognitive skills as they monitor their cognitive progress and question themselves the accuracy of their solution which in turn improves the students' academic achievement (Setiawan \& Supiandi, 2018; Sucianto, Irvan \& Rohim, 2019). In response to this issue, it is worth exploring students' metacognition especially when it involves mathematics problem-solving. This will help educators, especially, to plan strategies and instructions in solving a mathematics problem that will improve and encourage metacognitive skills among their students.

\section{Literature Review}

Metacognition is the act of choosing and planning what to do while monitoring what is being done in which plays a significant part in the mental activity involving the application of algorithms and heuristics (Garofalo \& Lester, 1985). Garofalo and Lester further stated the two facets of metacognition include knowledge and beliefs about cognitive phenomena and the regulation and control of cognitive actions. Metacognitive knowledge refers to the segment of stored world knowledge connected to people as cognitive creatures and their various cognitive tasks, goals, actions, and experiences (Flavell, 1979). Flavell further elaborated it contains the knowledge or beliefs about the person, task, or strategy that act and interact in unique ways thus influencing the course and outcome of cognitive enterprises, e.g. memory and comprehension. The individual will then experience the metacognitive as the items of metacognitive knowledge reach consciousness. When an individual experiences the metacognition, a metacognitive strategy is activated that acts to monitor the cognitive progress (Flavell, 1979).

The learning of mathematics focus on seeking solutions, exploring patterns, and formulate conjecture (Schoenfeld, 1992). This highlights the importance of integrating problem-solving in a mathematics lesson. Polya (1981) explained to solve a problem means to find the action that is appropriate to achieve an aim. This then is a task that is experienced by an individual which will activate the cognitive strategy to find the action that is appropriate to achieve the aim. The metacognition applies when this individual wonders about the accuracy of their action and hence monitors the cognitive progress as a metacognitive strategy. However, not all individuals aware of their metacognition and therefore unable to monitor their cognitive progress to reach the 
INTERNATIONAL JOURNAL OF ACADEMIC RESEARCH IN PROGRESSIVE EDUCATION AND

DEVELOPMENT

Vol. 9, No. 3, 2020, E-ISSN: $2226-6348 @ 2020$ HRMARS

appropriate action in achieving the aim of a problem. The absence of this awareness therefore disables an individual to plan, sequence, and monitor their learning that could have improved their performance (Schraw \& Dennison, 1994). Therefore, this study will review previous researches systematically to understand students' metacognition during mathematics problemsolving sessions.

\section{Research Questions}

To understand students' metacognition in mathematics problem solving, there are two research questions in this study that are to be answered based on the systematic review of the literature. The research questions are How students' metacognition can be improved when solving a mathematical problem? What are the challenges faced by students from developing metacognitive skills in solving mathematical problems?

\section{Methodology}

Moher et. al. (2015) and Shamseer et. al. (2015) issued a protocol to review articles systematically which commonly acronym as PRISMA. To understand students' metacognition in mathematics problem solving, researcher conducted the review following the protocols by PRISMA. Based on the conditions set for the review process, resources were obtained from Scopus and ERIC databases considering the eligibility criteria.

\section{PRISMA}

This review was conducted based on the Preferred Reporting Items for Systematic review and Meta-Analysis Protocols (PRISMA-P) explained by Shamseer et. al. (2015). Among other reporting standard, PRISMA allows at least 27 items for systematic review which is the lowest in systematic reviews and meta-analyses reporting, and while it focusses on randomised trials, this protocol is also suggested for study involving assessments of interventions in other fields of study (Shaffril, Samsuddin \& Abu Samah, 2020).

\section{Resources}

This study focusses on the articles obtained from Scopus and ERIC databases. Currently, the highest content coverage listed in Scopus is studies in Social Science that up to 32\% compared to another three other subject areas that are Physical Sciences (27\%), Health Sciences (25\%) and Life Sciences (16\%). Meanwhile, with a collection of 1.8 million records of various type of publications, ERIC is claimed to be the largest education database in the world. In general, the educational articles from both of these databases were properly organized whereby each article were grouped based on their unique and common categories that include year of publication, languages, authors, subject areas, type of articles and peer reviewed which helps refine the search of desired articles efficiently. These two databases are able to provide qualified articles for review in this study to understand the students' metacognition in mathematics problem solving. As it is time consuming and demanding to ensure the quality of each published studies in both databases with vast record, , Okoli and Schabram (2010) mentioned all reviewed articles were considered as qualified as these articles had been reviewed by qualified reviewers. In this 
study, all the articles provided by the two databases were peer-reviewed and therefore it can be considered that the articles selected in this study were qualified to be included if it corresponds to the research questions of this study.

\section{Inclusion and Exclusion Criteria}

The articles collected from these two databases had been filtered based on the inclusion and exclusion criteria set by this study which was summarised in Table 1 . These criteria include the publication type, period of publication and language. In this study, only journal articles with empirical data were included in the review whereas concept papers, conference proceeding and reflection papers were excluded. In order to preserve the consistency of the review and avoid misinterpretation of context, this study only include articles published in English and exclude articles that were published in other language (not English) which was set as the second criteria. Lastly, this study only includes articles that were published from 2017 to Jun 2020, and the period under and beyond of these criteria were excluded. As this study was conducted in Jun 2020, there were articles yet to be published beyond the period of interest of this study. Furthermore, the number of articles within this period were sufficient to understand students' metacognition in mathematics problem solving following the concept of research fields maturity by Kraus et. al. (2020).

Table 1: The Inclusion and Exclusion Criteria

\begin{tabular}{|c|c|c|}
\hline Inclusion & Criteria & Exclusion \\
\hline $\begin{array}{c}\text { Journal Articles with } \\
\text { empirical data (peer } \\
\text { reviewed) }\end{array}$ & Type of Publication & $\begin{array}{c}\text { Concept papers, } \\
\text { conference proceeding } \\
\text { and reflection papers }\end{array}$ \\
\hline English & Language & Apart from English \\
\hline 2017 - Jun 2020 & Period of Publication & 2016 and below \\
\hline
\end{tabular}

\section{Systematic Review Process}

The process of the systematic review in this study performed in four phases. It began with identifying the keywords applied to retrieve the relevant articles in both databases. The keywords were identified based on the previous studies involving terms related to metacognition and mathematics problem solving.

Table 2: Keywords use to Search Relevant Articles

\begin{tabular}{|l|l|}
\hline Database & Keywords \\
\hline Scopus & $\begin{array}{l}\text { TITLE-ABS-KEY } \\
\text { ("mathematics" AND "metacognition" OR "metacognitive" AND "problems" ) }\end{array}$ \\
\hline ERIC & "mathematics" AND "metacognition" OR "metacognitive" AND "problems" \\
\hline
\end{tabular}

The results were then refined by using the limiter provided by each database based on the inclusion criteria in this study. After the number of articles was gradually narrowed, the articles 
provided by these two databases were then compared to remove any duplicated articles. At this phase, two identical articles were excluded from the review as both of these articles were duplicates. After careful screening at the second phase, a total of 54 articles were eligible for the review while 31 articles were eliminated. At the third phase, this study determines the eligibility of the full-text articles based on the criteria set earlier. During this phase, several numbers of articles were not of interest in this study and therefore these articles were excluded from the review process. These may include articles of a different topic, concept papers, reflection, or even measurement development. The only articles included in this study were empirical studies that correspond to the research questions. Consequently, 23 articles were removed. Hence, the last survey at the final phase resulting 31 articles were utilized to perform systematic review to understand students' metacognition in mathematics problem solving. Diagram 1 shows the process of screening of the finalized evidence that was reviewed in this study.

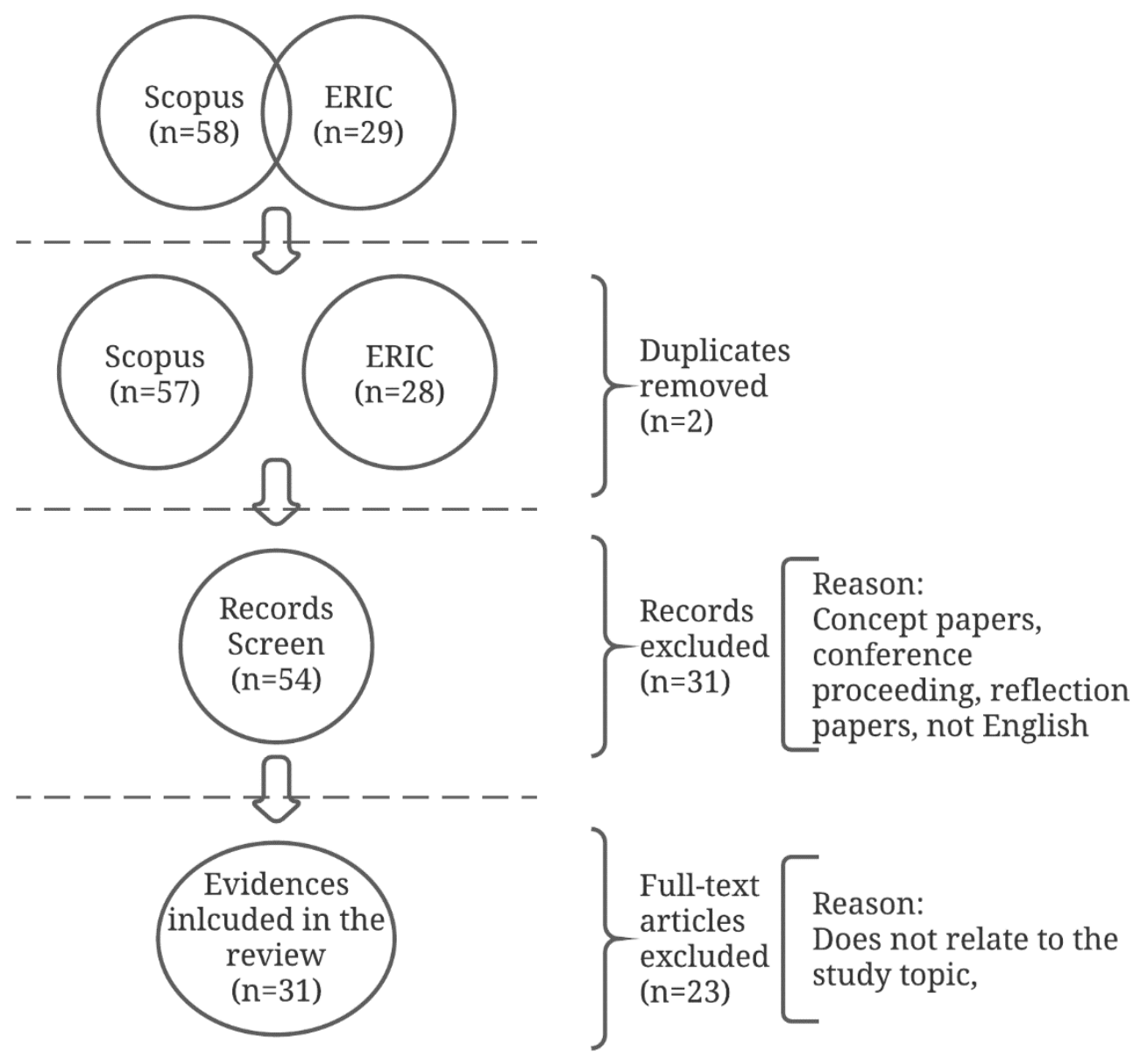

Diagram 1: Systematic Review Process

Since there were only two research questions in this study, the evidence that will be reviewed were grouped based on the research question that corresponds to it. The majority of the finding was a qualitative study with 13 articles, followed by 11 articles of quantitative research approach 
and lastly 7 articles that employed a mixed-method approach. There were 20 articles individually answering the first research question while there were 5 articles that correspond to the second research question. Also, 6 articles were discussing on both research questions in this study. Table 2 describes the number of articles based on the research questions they correspond to and their approaches. Based on Table 2, 'RQ1' represents research question 1, 'RQ2' represents research question 2, and 'Both' represents the evidence that corresponds to both research questions of this study. Finally, this study will review and synthesize these evidences by a group that was based on the two research questions of this study.

Table 2: Distribution of Study Approaches and Research Questions

\begin{tabular}{|l|c|c|c|c|}
\hline \multicolumn{1}{|c|}{ Approaches } & RQ1 & RQ2 & Both & Total \\
\hline Qualitative & 7 & 2 & 4 & 13 \\
\hline Quantitative & 8 & 1 & 2 & 11 \\
\hline Mixed Method & 5 & 2 & 0 & 7 \\
\hline \multicolumn{1}{|c|}{ Total } & 20 & 5 & 6 & 31 \\
\hline
\end{tabular}

\section{Results}

Research question 1: How the students' metacognition can be improved when solving a mathematical problem?

The evidence that corresponds to the first research questions will be described in this section. All the evidence explained the strategies, instruction, activities, or interventions that trigger and improve students' metacognition when solving a mathematical problem. Table 3 shows a list of evidence that corresponds to the first research question.

Table 3: List of evidences that correspond to the first research question

\begin{tabular}{|l|l|}
\hline \multicolumn{1}{|c|}{ Approach } & \multicolumn{1}{c|}{ Author } \\
\hline Qualitative, $\mathrm{n}=11$ & Acar \& Ader (2017), Gurat (2018), Daher, \\
& Anabousy \& Jabarin (2018), Jagals \& van der Walt \\
& (2018), Smith \& Mancy (2018), Tachie \& Molepo \\
& (2019), Ozdogan, Ozçakir \& Orhan (2019), Hacker, \\
& Kiuhara \& Levin (2019), Radmehr \& Drake (2020), \\
& Alghamdi, Jitendra \& Lein (2020), Hanin \& Van \\
& Nieuwenhoven (2020) \\
\hline Quantitative, $\mathrm{n}=10$ & Hassan \& Rahman (2017), Vula (2017), Al-Shabibi \\
& \& Alkharusi (2018), Baltaci (2018), Shilo \& \\
& Kramarski (2019), Zhao et. al. (2019), Chytrý, \\
& Ŕíčan \& Medová (2019), Callan \& Cleary (2019), \\
& Ahdhianto et. al. (2020), Toraman, Orakci \& Aktan \\
& (2020) \\
\hline Mixed Method, $\mathrm{n}=5$ & Erdoğan \& Şengül (2017), Tzohar-Rozen \& \\
& Kramarski (2017), Setiawan \& Supiandi (2018), \\
& Sucianto, Irvan \& Rohim (2019), Fung \& Poon \\
& (2020) \\
\hline
\end{tabular}


Previous studies have discussed how students' metacognition can be improved when they were acquired to solve the mathematical problem. This includes the intervention factor of the studies ranges from the strategies, instructions, and activities. This study was able to highlight themes based on the literature reviewed that correspond to the first research question. Several researchers explained that the characteristics of mathematical problems can improve the students' metacognitive skills such as the problem with inconsistent language and complex (Vula, 2017) and verbal problem solving (Tzohar-Rozen \& Kramarski, 2017).

Besides, it was also found that previous studies improving students' metacognition by integrated learning like cooperative learning (Erdoğan \& Şengül, 2017), Problem-Based Learning (Setiawan \& Supiandi, 2018), Research-Based Learning (Sucianto, Irvan \& Rohim, 2019), Self-Regulated Learning (Callan \& Cleary, 2019), Metacognitive-Based Contextual Learning (Ahdhianto et. Al., 2020) and Schema-Based Learning (Alghamdi, Jitendra \& Lein, 2020). Class activities will also improve students' metacognition which includes peer tutoring (Acar \& Ader, 2017), claiming leadership in a group (Daher, Anabousy \& Jabarin, 2018), collaborative talk (Smith \& Mancy, 2018), metacognitive discourse (Shilo \& Kramarski, 2019) and writing (Hacker, Kiuhara \& Levin, 2019). Integrating software like GeoGebra during mathematics problem solving could also improve students' metacognition (Baltaci, 2018).

Besides, students' factor could also be able to improve and initiate their metacognition whereby this metacognition will be able to be activated and improved when the students were equipped with imaginative capabilities (Jagals and van der Walt, 2018; Alghamdi, Jitendra \& Lein, 2020), responsible in their learning and reflective thinking of problem-solving (Toraman, Orakci \& Aktan, 2020). Nevertheless, a teacher also plays an important role in improving students' metacognition (Erdoğan \& Şengül, 2017; Tachie \& Molepo, 2019; Hacker, Kiuhara \& Levin, 2019; Chytrý, Říčan \& Medová, 2019). Furthermore, supplementary elements would also enhance students' metacognition (Fung \& Poon, 2020).

Therefore, based on this review, seven themes have been identified by this study explaining the enhancement of students' metacognition when solving mathematical problem-solving. These themes include the characteristics of mathematics problem, integrated learning, class activities, integrating software during mathematics problem solving, students' factor, teacher, and supplementary elements.

Research question 2: What are the challenges faced by the students from developing metacognitive skills in solving mathematical problems?

In this section, the challenges experienced by the students from developing metacognitive skills in solving mathematical problems will be explored based on previous studies. Table 4 shows the list of studies that corresponded to the second research question of this study. 
INTERNATIONAL JOURNAL OF ACADEMIC RESEARCH IN PROGRESSIVE EDUCATION AND

DEVELOPMENT

Vol. 9, No. 3, 2020, E-ISSN: $2226-6348$ @ 2020 HRMARS

Table 4: List of evidences that correspond to the second research question

\begin{tabular}{|l|l|}
\hline \multicolumn{1}{|c|}{ Approach } & \multicolumn{1}{c|}{ Author } \\
\hline Qualitative, $n=6$ & $\begin{array}{l}\text { Daher, Anabousy \& Jabarin (2018), Kuzle (2019), } \\
\text { Temur, Ozsoy \& Turgut (2019), Ozdogan, Ozçakir } \\
\text { \& Orhan (2019), Radmehr \& Drake (2020), Hanin } \\
\text { \& Van Nieuwenhoven (2020) }\end{array}$ \\
\hline Quantitative, $n=3$ & $\begin{array}{l}\text { Vula (2017), Ozcan \& Eren Gümüş (2019), Callan } \\
\text { \& Cleary (2019) }\end{array}$ \\
\hline Mixed Method, $n=2$ & Bessoondyal (2017), Nelson \& Fyfe (2019) \\
\hline
\end{tabular}

As students were unable to practice metacognition especially when dealing with a mathematical problem, this will affect their academic achievement in mathematics (Callan \& Cleary, 2019). But this was not due to the child alone as there were several challenges experienced by the students in practicing metacognition in solving mathematical problems. As such, students encounter difficulties in understanding keywords and interpreting them into mathematical language arithmetical operation (Vula, 2017; Hanin \& Van Nieuwenhoven, 2020). These students were found does not perform proper planning and did not seems aware of their cognitive progress properly as they tend to jump to a mathematical operation to be used without proper analysis of the question (Bessoondyal, 2017). The challenge becomes more difficult to overcome as students developing a collection of poor cognitive strategy which was shown through the attempt of mathematical problems with general or without a strategy (Hanin \& Van Nieuwenhoven, 2020). Also, forethought phase processes that were used by students were reported as not related to metacognitive monitoring (Callan \& Cleary, 2019). This takes effect as below average students constantly developing a plan in sequence compared to above-average students that develop plan all at once (Kuzle, 2019). This was then shown when the certainty and knowledge of elementary school children were not well calibrated as they seen not seeking help to attend to their feeling of certainty and thus encourage them to overestimate their abilities (Nelson \& Fyfe, 2019). A teacher also plays a role that contributes to the challenges faced by the students in developing metacognitive skills as it was seen that teachers did not display verification; an aspect to activate metacognitive strategy (Ozdogan, Ozçakir \& Orhan, 2019). Nevertheless, teacher's belief that seen commented on the students' performances individually, suggested strategies to students instead of allowing the students to suggest strategies to each other and having students work individually than communicating with each other largely challenged the students in applying metacognitive skills (Temur, Ozsoy \& Turgut, 2019).

It was also reported that the positive effect of a member in claiming to be as a group leader resulting in a negative effect on the other members and this may affect the emotions and metacognitive processes of the individual (Daher, Anabousy \& Jabarin, 2018). As mathematics anxiety on mathematical problem solving associated with motivation, self-efficacy, and metacognition (Ozcan \& Eren Gumus, 2019) indicated the low level of confidence among the students in solving mathematics problem due to repeated failures (Hanin \& Van Nieuwenhoven, 2020). Another study reported students' negative perception and emotion on summarizing, monitoring, and the need to know justifications behind formulas (Radmehr \& Drake, 2020; Hanin 
\& Van Nieuwenhoven, 2020) indicating the challenge even before the students ignites their metacognition.

The challenges experienced by the students found in this review can be summarized into two entities that were sourced from students themselves and their teachers. Challenges sourced from the students themselves include the difficulties of the students in understanding keywords and translating them into abstract mathematical language, their poor cognitive strategy, their certainty and knowledge of elementary school were not well calibrated and their negative perceptions that develop mathematics anxiety thus influence their emotions and level of confidence. The second source of the challenges was contributed by the teachers where the students observe their teacher as a role model and tend to adapt their style of teaching.

\section{Discussion and Conclusion}

Of 31 articles in total that have been reviewed in this study, there were 13 studies employed a qualitative approach, 11 studies were conducted quantitatively, and 7 articles employed both approaches. Based on the findings from the reviewed articles, most of the researches conducted on students' metacognition during problem-solving was focussed on the factor that influences and could improve the students' metacognition when solving mathematical problems. These include the characteristics and complexity of mathematics problems, integrated learning, class activities, integrating software during mathematics problem solving, students' factor, teacher, and supplementary elements. In contrast, there were fewer articles focussed on the challenges faced by the students in nurturing and applying metacognition when solving mathematical problems compared to the factor that influences the students' metacognition when solving mathematical problems. However, the review of these articles yields two sources in general which contribute to the significant issues that point to the challenges faced by the students as they were activating their metacognition when solving mathematical problems. These two sources were the students themselves and their teacher.

The ability to employ metacognitive skills was proven beneficial especially when solving a mathematics problem. As the students experience the metacognition, their metacognitive strategy helps them properly monitor their progress and the solution they had computed (Flavell, 1979) and hence lower the risk of doing mistakes in solving the mathematical problem. The findings of this study may support the government body to redesign and emphasize metacognition in their curriculum while also shapes the approach of educators in their teaching and learning. In response to the findings of this study, there are needs for future research to add to the literature which specifically discussing the challenges faced by students in developing metacognition when solving a mathematics problem. This topic is worth the study as it highlights the difficulties experienced by the students in developing metacognitive skills when solving a mathematics problem. This will then beneficial to the educators to identify the challenges faced by the students and help the teachers plan their teaching and learning in a way that could encourage and improve students' metacognition in solving mathematical problems. In addition, researchers may explore the prospective challenges faced by the students and their influences on students' metacognition in solving mathematical problems. This may include the role of the family in developing students' metacognition.

Acknowedgement 
INTERNATIONAL JOURNAL OF ACADEMIC RESEARCH IN PROGRESSIVE EDUCATION AND

DEVELOPMENT

Vol. 9, No. 3, 2020, E-ISSN: $2226-6348 @ 2020$ HRMARS

This study was funded by the grant of Faculty Education, Universiti Kebangsaan Malaysia GG2019-065.

\section{References}

Ahdhianto, E., Marsigit, H., \& Santi, N. N. (2020). The effect of metacognitive-based contextual learning model on fifth-grade students' problem-solving and mathematical communication skills. European Journal of Educational Research, 9(2), 753-764. https://doi.org/10.12973/eu-jer.9.2.753

Acar, F., \& Ader, E. (2017). Metacognition used by tutors during peer tutoring sessions in mathematics. [Matematikte akran oğretimi sırasında oğretici gorevi üstlenen ogrencilerde ustbilis] Elementary Education Online, 16(3), 1185-1200. doi:10.17051/ilkonline.2017.330250

Al Shabibi, A., \& Alkharusi, H. (2018). Mathematical problem-solving and metacognitive skills of 5 th grade students as a function of gender and level of academic achievement. Cypriot Journal of Educational Science. 13(2), 385-395.

Alghamdi, A., Jitendra, A. K., \& Lein, A. E. (2020). Teaching students with mathematics disabilities to solve multiplication and division word problems: the role of schema-based instruction. ZDM. doi:10.1007/s11858-019-01078-0

Baltaci, S. (2018). The Impact of Teaching Geometric Locus Problems in a Computer-Assisted Environment on the Metacognitive Awareness of Preservice Teachers. Acta Didactica Napocensia, 11(2), 121-134.

Bessoondyal, H. (2017). Meta-Cognitive Strategies in Problem Solving for Children with Learning Difficulties in Mathematics at the Primary Level. International Journal of Special Education, 32(1), 37-54.

Callan, G. L., \& Cleary, T. J. (2019). Examining cyclical phase relations and predictive influences of self-regulated learning processes on mathematics task performance. Metacognition and Learning, 14(1), 43-63.

Chytry, V., Rican, J., \& Medova, J. (2019). How Teacher's Progressiveness in Using Digital Technologies Influences Levels of Pupils' Metacognitive Knowledge in Mathematics. Mathematics, 7(12), 1245.

Daher, W., Anabousy, A., \& Jabarin, R. (2018). Metacognition, Positioning and Emotions in Mathematical Activities. International Journal of Research in Education and Science, 4(1), 292-303.

Erdogan, F., \& Sengul, S. (2017). The Effect of Cooperative Learning Method Enhanced with Metacognitive Strategies on Students' Metacognitive Skills in Math Course. Education \& Science/Egitim ve Bilim, 42(192).

Flavell, J. H. (1979). Metacognition and cognitive monitoring: A new area of cognitivedevelopmental inquiry. American Psychologist, 34(10), 906-911. doi:10.1037/0003066x.34.10.906

Fung, C. H., \& Poon, K. K. (2020). Can dynamic activities boost mathematics understanding and metacognition? A case study on the limit of rational functions. International Journal of Mathematical Education in Science and Technology, 1-15. 
INTERNATIONAL JOURNAL OF ACADEMIC RESEARCH IN PROGRESSIVE EDUCATION AND

DEVELOPMENT

Vol. 9, No. 3, 2020, E-ISSN: $2226-6348 @ 2020$ HRMARS

Garofalo, J., \& Lester, F. (1985). Metacognition, Cognitive Monitoring, and Mathematical Performance. Journal for Research in Mathematics Education, 16(3), 163-176. doi:10.2307/748391

Gurat, M. G. (2018). Mathematical Problem-Solving Strategies among Student Teachers. Journal on Efficiency and Responsibility in Education and Science, 11(3), 53-64.

Hacker, D. J., Kiuhara, S. A., \& Levin, J. R. (2019). A metacognitive intervention for teaching fractions to students with or at-risk for learning disabilities in mathematics. ZDM, 51(4), 601-612.

Hanin, V., \& Van Nieuwenhoven, C. (2020). An Exploration of the Cognitive, Motivational, Emotional and Regulatory Behaviours of Elementary-School Novice and Expert Problem Solvers. Canadian Journal of Science, Mathematics and Technology Education, 1-30.

Hassan, N. M., \& Rahman, S. (2017). Problem solving skills, metacognitive awareness, and mathematics achievement: A mediation model. The New Educational Review, 49(3), 201212.

Jagals, D., \& Van der Walt, M. (2018). Metacognitive awareness and visualisation in the imagination: The case of the invisible circles. Pythagoras, 39(1), 1-10.

Kraus, S., Breier, M., Dasí-Rodríguez, S. (2020). The art of crafting a systematic literature review in entrepreneurship research. International Entrepreneurship and Management Journal. 16(3), 1023-1042. https ://doi.org/10.1007/s11365-020-00635 -4

Kuzle, A. (2019). Second Graders' Metacognitive Actions in Problem Solving Revealed through Action Cards. The Mathematics Educator, 28(1), 27-60.

Moher, D., Shamseer, L., Clarke, M., Ghersi, D., Liberati, A., Petticrew, M., Shekelle, P., Stewart, L. A. (2015) Preferred Reporting Items for Systematic Review and Meta-Analysis Protocols (PRISMA-P) 2015 statement. Syst Rev. 4(1):1. doi: 10.1186/2046-4053-4-1

Nelson, L. J., \& Fyfe, E. R. (2019). Metacognitive monitoring and help-seeking decisions on mathematical equivalence problems. Metacognition and Learning, 14(2), 167-187.

Okoli, C., Schabram, K. (2010). "A Guide to Conducting a Systematic LiteratureReview of Information Systems Research," Sprouts: Working Papers on InformationSystems, 10(26). http://sprouts.aisnet.org/10-26

Ozcan, Z. C., \& Eren Gumus, A. (2019). A modeling study to explain mathematical problem-solving performance through metacognition, self-efficacy, motivation, and anxiety. Australian Journal of Education, 63(1), 116-134.

Ozdogan, S. S., Ozcakir, B., \& Orhan, B. (2019). A case of teacher and student mathematical problem-solving behaviors from the perspective of a cognitive-metacognitive framework.

Polya, G. (1981). Mathematical discovery (combined edition).

Radmehr, F., \& Drake, M. (2020). Exploring Students' Metacognitive Knowledge: The Case of Integral Calculus. Education Sciences, 10(3), 55.

Schoenfeld, A. H. (1992). Learning to think mathematically: Problem solving, metacognition, and sense making in mathematics. Handbook of research on mathematics teaching and learning, 334370.

Schraw, G., \& Dennison, R. S. (1994). Assessing metacognitive awareness. Contemporary educational psychology, 19(4), 460-475. 
INTERNATIONAL JOURNAL OF ACADEMIC RESEARCH IN PROGRESSIVE EDUCATION AND

DEVELOPMENT

Vol. 9, No. 3, 2020, E-ISSN: $2226-6348$ @ 2020 HRMARS

Setiawan, B., \& Supiandi, M. I. (2018). The Contribution of Metacognitive Skills and Reasoning Skills on Problem Solving Ability Based on Problem Based Learning (PBL) Model. Anatolian Journal of Education, 3(2), 75-86.

Shaffril, H. A. M., Samsuddin, S. F., \& Samah, A. A. (2020). The ABC of systematic literature review: the basic methodological guidance for beginners. Quality \& Quantity, 1-28. https://doi.org/10.1007/s11135-020-01059-6

Shamseer, L., Moher, D., Clarke, M., Ghersi, D., Liberati, A., Petticrew, M., Shekelle, P., Stewart, L., PRISMA-P Group. (2015). Preferred reporting items for systematic review and metaanalysis protocols (PRISMA-P): elaboration and explanation. BMJ. 2015.349:g7647. doi: 10.1136/bmj.g7647

Shilo, A., \& Kramarski, B. (2019). Mathematical-metacognitive discourse: how can it be developed among teachers and their students? Empirical evidence from a videotaped lesson and two case studies. ZDM, 51(4), 625-640.

Smith, J. M., \& Mancy, R. (2018). Exploring the relationship between metacognitive and collaborative talk during group mathematical problem-solving-what do we mean by collaborative metacognition? Research in Mathematics Education, 20(1), 14-36.

Sucianto, B., Irvan, M., \& Rohim, M. A. (2019). The Analysis of Student Metacognition Skill in Solving Rainbow Connection Problem under the Implementation of Research-Based Learning Model. International Journal of Instruction, 12(4).

Tachie, S. A., \& Molepo, J. M. (2019). Exploring Teachers' Meta-Cognitive Skills in Mathematics Classes in Selected Rural Primary Schools in Eastern Cape, South Africa. Africa Education Review, 16(2), 143-161.

Temur, O. D., Ozsoy, G., \& Turgut, S. (2019). Metacognitive instructional behaviours of preschool teachers in mathematical activities. ZDM, 51(4), 655-666.

Toraman, C., Orakci, S., \& Aktan, O. (2020). Analysis of the Relationships between Mathematics Achievement, Reflective Thinking of Problem Solving and Metacognitive Awareness. International Journal of Progressive Education, 16(2), 72-90.

Tzohar-Rozen, M., \& Kramarski, B. (2017). Meta-cognition and meta-affect in young students: does it make a difference on mathematical problem solving. Teachers College Record, 119(13), 1-26.

Vula, E., Avdyli, R., Berisha, V., Saqipi, B., \& Elezi, S. (2017). The impact of metacognitive strategies and self-regulating processes of solving math word problems. International Electronic Journal of Elementary Education, 10(1), 49-59.

Zhao, N., Teng, X., Li, W., Li, Y., Wang, S., Wen, H., \& Yi, M. (2019). A path model for metacognition and its relation to problem-solving strategies and achievement for different tasks. ZDM, 51(4), 641-653. 